\title{
Edukasi tentang Pemberian Imunisasi DPT di Posyandu Penyengat Rendah Wilayah Kerja Puskesmas Aur Duri Kota Jambi
}

\author{
Tuhu Perwitasari \\ Prodi D III Kebidanan STIKes Baiturrahim Jambi \\ Email: tuhuperwitasari@gmail.com
}

Submitted : 13/01/2021

Accepted: 08/01/2022

Published: 28/01/2022

\begin{abstract}
Immunization is an effort to actively cause or increase a person's immunity to a particular disease so that if one day is exposed to the disease it will not be sick or only experience mild illness. DPT immunization can prevent diphtheria, pertussis and tetanus which can cause disability and even death. by giving immunizations will reduce the incidence of morbidity, disability, and deaths due to PD3I which is estimated to be 2 to 3 million deaths each year. in the Aurduri Puskesmas working area until 2018 the decline in immunization coverage was highest in the city of jambi because of the lack of knowledge about immunization. output targets are expected to increase knowledge between before and after counseling, as well as the awareness of mothers to bring their children to Posyandu for immunization. The method used is counseling. the result of dedication there is an increase in knowledge and awareness of the mother to bring her child to be immunized in an effort to prevent disease.
\end{abstract}

Keywords: DPT, education, immunization

\begin{abstract}
Abstrak
Imunisasi merupakan upaya menimbulkan atau meningkatkan kekebalan seseorang secara aktif terhadap suatu penyakit tertentu sehingga bila suatu saat terpapar dengan penyakit tersebut tidak akan sakit atau hanya mengalami sakit ringan. Imunisasi DPT dapat mencegah penyakit difteri, pertusis dan tetanus yang dapat menimbulkan kecacatan bahkan kematian. Dengan memberikan imunisasi akan mengurangi kejadian kesakitan, kecacatan, dan kematian akibat PD3I yang diperkirakan 2 hingga 3 juta kematian tiap tahunnya. Di wilayah Kerja Puskesmas Aurduri sampai pada tahun 2019 masih mengalami penurunan cakupan imunisasi tertinggi di kota jambi hal ini terjadi karna masih kurangnya pengetahuan tentang imunisasi. Target luaran yang diharapkan peningkatan pengetahuan antara sebelum dan setelah penyuluhan, serta kesadaran ibu untuk membawa anaknya ke Posyandu untuk mendapatkan imunisasi. Metode yang digunakan adalah penyuluhan. Hasil pengabdian terdapat peningkatan pengetahuan dan kesadaran ibu untuk membawa anaknya mendapatkan imunisasi dalam upaya pencegahan penyakit.
\end{abstract}

Kata Kunci: edukasi, imunisasi, DPT

\section{PENDAHULUAN}

Imunisasi merupakan upaya untuk menimbulkan atau meningkatkan kekebalan seseorang secara aktif terhadap suatu penyakit. Sehingga bila suatu saat terpapar dengan penyakit tersebut tidak akan sakit atau hanya mengalami sakit ringan. Setiap tahun lebih dari 1,4 juta anak di dunia meninggal karena berbagai penyakit yang dapat dicegah dengan imunisasi. Survei Demografi dan Kesehatan Nasional (SDKI) menunjukkan prevalensi imunisasi secara umum termasuk ke dalam Penyakit yang dapat dicegah dengan Imunisasi
(PD3I) salah satunya adalah Difteri, Tetanus, Pertusis. Anak yang telah memperoleh imunisasi akan terlindungi dari berbagai penyakit berbahaya yang berakibat kecacatan atau kematian (Kemenkes RI, 2016).

Berdasarkan Kemenkes RI tahun 2018 cakupan imunisasi DPT di provinsi jambi $106,8 \%$. Sedangkan, cakupan imunisasi di Kota Jambi tahun 2016-2017 pelaksanaan imunisasi DPT1 mencapai $100,71 \%$ menurun menjadi $97,82 \%$, Imunisasi DPT2 mencapai $100,41 \%$ menurun menjadi $97,54 \%$, Imunisasi DPT3 mencapai $100,05 \%$ menurun menjadi $97,41 \%$. 
Kabid Pencegahan Pengendalian Penyakit Dinas Kesehatan Kota Jambi 2017, menjelaskan bahwa sebanyak 4.770 Balita (0-9 bulan) di Kota Jambi belum mendapat imunisasi. Dari 15.025 balita yang harus mendapatkan imunisasi dasar baru 10.255 balita yang sudah. Sementara yang belum melakukan imunisasi mencapai 4.770 balita Wilayah Puskesmas Aur Duri merupakan puskesmas yang paling banyak terjadi penurunan cakupan imunisasi dasar pada tahun 2016 sampai dengan 2017. Tahun 2016 mencapai $102.31 \%$ menurun menjadi $98.51 \%$ pada tahun 2017 (Dinkes,2017).

Vaksinasi DPT (difteri, pertusis dan tetanus) dapat dilakukan dengan penyuntikan di paha kanan atau kiri. Sebagai salah satu kelompok yang menjadi sasaran program imunisasi, setiap bayi wajib mendapatkan imunisasi dasar lengkap termasuk imunisasi DPT.

Vaksin DPT disuntikkan pada bagian paha lokasi tertentu atau diteteskan melalui mulut. Sebagai salah satu kelompok yang menjadi sasaran program imunisasi, setiap bayi wajib mendapatkan imunisasi dasar lengkap yang terdiri dari 1 dosis BCG, 3 dosis DPT-HB dan atau DPT-HB-Hib, 4 dosis polio, dan 1 dosis campak. Dari imunisasi dasar lengkap yang diwajibkan tersebut, campak merupakan imunisasi yang mendapat perhatian lebih, hal ini sesuai komitmen Indonesia pada global untuk mempertahankan cakupan imunisasi campak sebesar $90 \%$ secara tinggi dan merata. Hal ini terkait dengan realita bahwa campak adalah salah satu penyebab utama kematian pada balita. Dengan demikian pencegahan campak memiliki peran signifikan dalam penurunan AKB. Indonesia memiliki cakupan imunisasi campak yang sedikit lebih rendah daripada tahun 2014, yaitu sebesar $92,3 \%$ pada tahun 2015 (Kemenkes RI, 2016).

Imunisasi dasar sebaiknya diberikan sesuai dengan umurnya, sehingga sistem kekebalan tubuh dapat bekerja secara optimal. Pada kondisi tertentu beberapa bayi tidak mendapatkan imunisasi dasar secara lengkap. Masih terdapat pemahaman yang berbeda dimasyarakat mengenai imunisasi, sehingga masih banyak bayi dan balita yang tidak mendapatkan pelayanan imunisasi. Alasan yang disampaikan orang tua mengenai hal tersebut, antara lain karena anaknya takut panas, sering sakit, keluarga tidak mengizinkan, tempat imunisasi jauh, tidak tahu tempat imunisasi, serta sibuk/repot. Karena itu, pelayanan imunisasi harus ditingkatkan di berbagai unit pelayanan (Kemenkes RI, 2015).

Imunisasi selain memiliki manfaat, juga menimbulkan efek samping dalam pelaksanaannya. Fenomena ini dikenal juga dengan istilah adverse event atau lebih dikenal dengan kejadian ikutan pasca imunisasi (KIPI). Dari 91,3 persen anak di Indonesia yang pernah diimunisasi, terdapat 33,4 persen yang pernah mengalami KIPI. Keluhan yang sering terjadi adalah kemerahan dan bengkak, sedangkan keluhan demam tinggi dialami 6,8 persen anak (Riskesdas, 2013).

Berdasarkan hasil observasi, telah banyak ibu yang membawa bayinya ke tenaga kesehatan untuk mendapatkan imuniasi, namun hanya sebagian kecil dari mereka yang diberikan konseling mengenai imunisasi. Akibat dari kurangnya pengetahuan tentang imunisasi banyak ibu yang kemudian panik dan menyalahkan tenaga kesehatan bahkan enggan membawa anaknya untuk di imunisasi untuk efek samping dari imunisasi yang mungkin bisa terjadi.

Pengetahuan Ibu tentang imunisasi merupakan faktor yang sangat penting, agar ibu dapat cepat tanggap dan tahu apa yang harus dilakukan ketika timbul efek samping pada anaknya untuk mendapatkan cakupan kelengkapan imunisasi. Kurangnya pengetahuan orang tua terutama ibu akan membawa sikap negatif dan rasa takut akan efek samping imunisasi yang nantinya akan berdampak pada pandangan ibu dan kemauan ibu untuk membawa anaknya ke fasilitas kesehatan guna mendapatkan imunisasi. Sehingga ada ibu yang berpandangan bahwa imunisasi akan menjadi hal yang merugikan bagi anaknya (Septiarini, 2015).

Pemberian pendidikan kesehatan melalui penyuluhan tentang imunisasi DPT merupakan upaya promotif untuk meningkatkan pengetahuan tentang imunisasi DPT dan preventif untuk pencegahan penyakit, sehingga mampu menumbuhkan kesadaran ibu membawa anaknya ke Posyandu untuk mendapatkan imunisasi dasar secara lengkap (Fitriani, 2013). 


\section{TARGET DAN LUARAN}

Target dalam kegiatan pengabdiaan kepada masyarakat ini adalah memberikan penyuluhan kesehatan tentang Edukasi Tentang Pemberian Imunisasi DPT kepada ibu-ibu agar membawa anaknya ke Posyandu untuk mendapatkan imunisasi dasar secara lengkap dan tidak mengkhawatirkan efek samping dalam upaya pencegahan penyakit. Adapun luaran dalam kegiatan pengabdian kepada ini adalah publikasi pada jurnal ilmiah dan meningkatkan kesadaran ibu untuk membawa anaknya ke tenaga kesehatan untuk mendapatkan imunisasi dalam upaya pencegahan penyakit.

\section{METODE PELAKSANAAN}

Pengabdian kepada masyarakat ini dilaksanakan pada bulan Mei 2019 di Posyandu Kelurahan Penyengat Rendah Wilayah Kerja Puskesmas Aur Duri Kota Jambi. Sasaran kegiatan ini adalah ibu-ibu yang memiliki bayi dan balita di Posyandu Penyengat Rendah.

Kegiatan pengabdian kepada masyarakat ini, mendapat rekomendasi dari Kepala puskesmas Aur Duri dan Kader setempat untuk memberikan informasi tentang Pemberian Imunisasi DPT melalui penyuluhan kepada ibuibu yang memiliki bayi dan balita di Posyandu Kelurahan Penyengat Rendah. metode yang digunakan dalam penyuluhan ini adalah ceramah, diskusi dan tanya jawab menggunakan media power point.

Tahapan kegiatan pengabdian kepada masyarakat meliputi:

1. Mengkaji dan menganalisis data

2. Mengidentifikasi masalah

3. Menyusun rencana kegiatan

4. Menyusun SAP, materi, instrumen prepost test serta membuat power point

5. Mengurus izin lokasi kegiatan

6. Melakukan pretest

7. Melakukan penyuluhan tentang imunisasi DPT menggunakan power point sesuai SAP yang telah disusun

8. Melakukan post test

9. Melakukan monitoring dan evaluasi

\section{HASIL DAN PEMBAHASAN}

Pelaksanaan kegiatan pengabdian kepada masyarakat berjalan sesuai dengan rencana yang disusun. Kegiatan ini dilaksanakan kepada 20 ibu yang memiliki bayi dan balita di Posyandu Kelurahan Penyengat Rendah Wilayah Kerja Puskesmas Aur Duri. Dalam pelaksanaan kegiatan ini Tim dibantu oleh mahasiswa, bidan desa dan kader yang sedang bertugas di Posyandu tersebut.

Sebelum dilakukan penyuluhan tentang imunisasi tim melakukan pretest. Hasilnya hanya $40 \%$ ibu mampu menjelaskan pengertian imunisasi DPT, 35\% ibu mampu menyebutkan tujuan imunisasi DPT, $25 \%$ ibu mampu menguraikan penyakit yang dapat dicegah dengan imunisasi DPT, 60\% ibu mampu menyebutkan tempat mendapatkan imunisasi DPT, $45 \%$ ibu mampu menyebutkan jadwal imunisasi DPT, 45\% ibu mampu menerangkan keadaan yang tidak memperbolehkan anak diimunisasi, dan $45 \%$ ibu mampu menerangkan keadaan yang muncul setelah imunisasi DPT.

Penyuluhan dalam pengabdian kepada masyarakat ini dilakukan dengan metode ceramah untuk menjelaskan ide, pengertian secara lisan disertai dengan diskusi dan tanya jawab sehingga ibu memahami apa yang diberikan dan disampaikan. Selain itu, materi yang diberikan ditampilkan melalui media power point yang berisi informasi penting tentang imunisasi DPT disertai gambar-gambar menarik sehingga ibu mudah menangkap informasi yang diberikan. Selama proses penyuluhan berlangsung ibu-ibu sangat antusias mendengarkan sambil memberikan tanggapan baik dalam diskusi, $75 \%$ ibu bertanya terkait dengan materi yang disampaikan.

Setelah diberikan informasi tentang imunisasi DPT tim melakukan posttest. Hasilnya mengalami peningkatan yaitu sebagian besar ibu mampu menjelaskan pengertian imunisasi DPT yaitu $80 \%$, ibu mampu menyebutkan tujuan imunisasi DPT sebanyak 85\%, sebagian besar ibu mampu menguraikan penyakit yang dapat dicegah dengan imunisasi DPT sebanyak 80\%, sebanyak $90 \%$ ibu mampu menyebutkan tempat mendapatkan imunisasi DPT, 90\% ibu mampu menyebutkan jadwal imunisasi, 90\% ibu mampu menerangkan keadaan yang tidak memperbolehkan anak diimunisasi DPT, dan 
$80 \%$ ibu mampu menerangkan keadaan yang muncul setelah imunisasi DPT. Serta $100 \%$ ibu memiliki kesadaran membawa anaknya untuk mendapatkan imunisasi DPT.

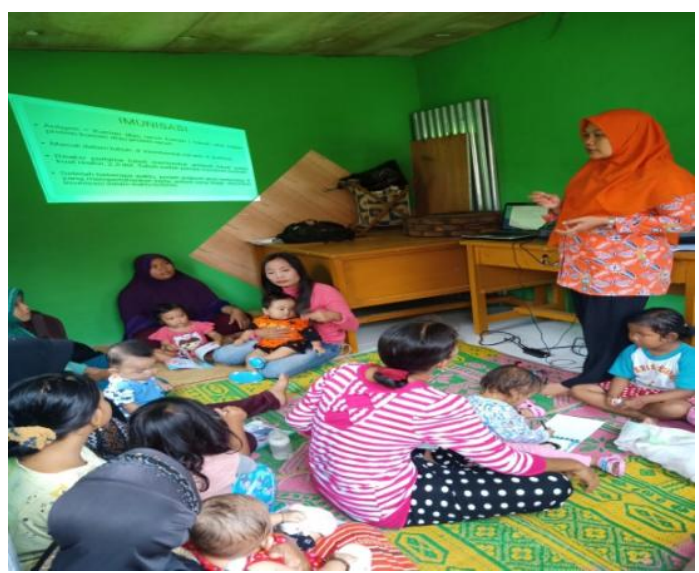

Gambar.1 Kegiatan Pengabdian

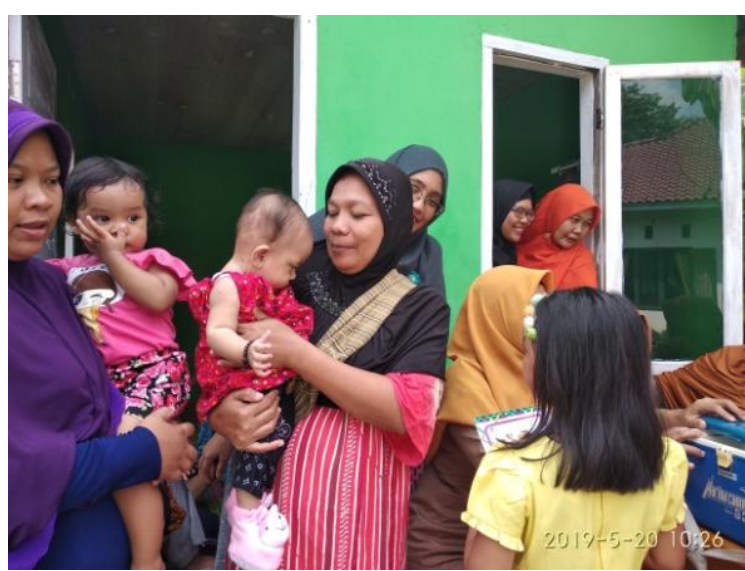

Gambar.2 Kegiatan Pengabdian

Hasil ini sejalan dengan penelitian yang dilakukan oleh Simanjuntak dan nurnisa, dinyatakan bahwa terdapat perbedaan yang signifikan pengetahuan ibu tentang imunisasi sebelum dan setelah diberikan penyuluhan $(\mathrm{p}<0,05)$. Salah satu faktor yang memengaruhi pengetahuan adalah karena kekurangan informasi. ibu masih banyak yang kurang memahami tentang kebutuhan, kelengkapan dan jadwal imunisasi, ketakutan akan imunisasi dan adanya persepsi salah yang beredar di masyarakat tentang imunisasi. Prmosi kesehatan dapat Pemberian informasi melalui pendidikan dan pelatihan untuk meningkatkan pengetahuan, selanjutnya akan menimbulkan kesadaran dan akhirnya ibu akan melakukan praktek sesuai dengan pengetahuan yang dimiliki, meskipun memerlukan waktu yang tidak sebentar dan harus berulang.

Hasil penelitian serupa oleh Marta, dinyatakan ada pengaruh penyuluhan tentang imunisasi campak terhadap peningkatan pengetahuan ibu $(p<0,05)$. Salah satu strategi untuk memperoleh perubahan perilaku adalah pemberian informasi untuk meningkatkan pengetahuan sehingga menimbulkan kesadaran dan dapat dilakukan dengan cara pemberian penyuluhan kesehatan.

Penelitian oleh Sukmaningtyas dkk, juga menujukkan terdapat pengaruh pemberian penyuluhan imunisasi terhadap peningkatan pengetahuan ibu tentang imunisasi dasar lengkap pada bayi $(\mathrm{p}<0,05)$. Para ibu bayi mau datang menimbangkan bayinya secara rutin, bahkan merelakan bayinya mendapatkan imunisasi dasar lengkap tepat waktu, bukan karena pengetahuan yang mereka dapat tapi karena kebanyakan ibu mau melakukannya, sebagai ajang berkumpul para ibu terlebih ada rangsangan pemberian makanan tambahan untuk anak mereka, meskipun disisi lain ada kekuatiran saat bayinya diberi imunisasi DPT timbul panas pada tubuh bayi. Hal ini mungkin bisa jadi perhatian bagi tenaga kesehatan untuk melakukan penyuluhan secara rutin untuk menjawab kekhawatiran tersebut dan meningkatkan kesadaran ibu membawa anaknya ke Posyandu untuk mendapatkan imunisasi dasar secara lengkap.

\section{KESIMPULAN DAN SARAN}

\section{Kesimpulan}

Pelaksanaan kegiatan pengabdian kepada masyarakat yang dilakukan melalui penyuluhan tentang imunisasi DPT kepada ibu-ibu balita di Posyandu Kasih Ibu mampu meningkatkan pengetahuan dan kesadaran ibu untuk membawa anaknya mendapatkan imunisasi dalam upaya pencegahan penyakit.

\section{Saran}

Disarankan kepada instansi yang terkait lebih mengoptimalkan peran tenaga kesehatan dalam memberikan penyuluhan secara rutin khususnya tentang imunisasi sehingga ibu-ibu balita lebih mengetahui dan mau membawa anaknya untuk mendapatkan imunisasi dasar 
secara lengkap tanpa mengkhawatirkan efek samping pemberian.

\section{UCAPAN TERIMAKASIH}

Tim pengabdian masyarakat mengucapkan terima kasih yang sebesarbesarnya kepada kepala puskesmas aur duri, bidan desa, kader posyandu dan ibu-ibu yang membawa balitanya ke posyandusebagai subjek pengabmas sehingga kegiatan pengabdian masyarakat ini dapat berjalan dengan lancar sesuai dengan waktu yang telah direncanakan.

\section{DAFTAR PUSTAKA}

Fitriani, S. 2013. Promosi Kesehatan. Graha Ilmu. Yogyakarta.

Kementerian Kesehatan RI. 2016. Profil Kesehatan Indonesia 2015. Kesehatan Kementerian Kesehatan RI. Jakarta.

Kementrian Kesehatan RI. 2013. Riset Kesehatan Dasar 2013. Badan Penelitian dan Pengembangan Kesehatan Kementrian Kesehatan RI.

Sarfaraz MD, Athira A, Thotamsetty LMD, Ravilla SA, Nadikudi N, Doddayya D. Assessment of Knowledge, Attitude and Perception among Mothers towards Immunization in a Tertiary Care Teaching Hospital. Int J Community Med Publich Health. 2017;4(9):3429-35. Septiarini RDP, Susanti AI, Nirmala SA. Pengaruh Penyuluhan Mengenai Imunisasi terhadap Pengetahuan dan Sikap Ibu di Desa Sukarapih Kecamatan Sukasari. JSK. 2015;1(2):43-54.

Sukmaningtyas W, Setiawan I. Pengaruh Penyuluhan Imunisasi terhadap Peningkatan Pengetahuan dan Kepatuhan Ibu tentang Imunisasi Dasar Lengkap pada Bayi Sebelum Usia 1 Tahun di Kecamatan Karangmoncol. Vina Medika. 2015;8(14):68-76. 